\title{
MAPEAMENTO E QUANTIFICAÇÃO DA COBERTURA VEGETAL EM ÁREAS PERIFÉRICAS NA CIDADE DE PARAGOMINAS - PA
}

\author{
MAPPING AND QUANTIFICATION OF ARBOREOUS VEGETAL COVERING IN \\ SUBURBS OF PARAGOMINAS CITY, PA
}

\author{
Lucimar Costa Pereira ${ }^{1}$, Maycon Viana Balbino², Nayara do Socorro Nascimento Farias ${ }^{3}$, Lorena Saraiva \\ Viana ${ }^{4}$, Maria Renata da Rocha Xavier ${ }^{5}$, Denison Lima Correa ${ }^{6}$, Tulio Marcus Lima da Silva ${ }^{7}$
}

\section{RESUMO}

Um importante mecanismo envolvido no avanço da urbanização é a substituição de áreas de vegetação por equipamentos urbanos, ação que se torna mais crítica nas periferias, onde a execução do planejamento urbano e a manutenção das condições de conforto e qualidade ambiental tendem a ser mais deficientes. Dado isto, esta pesquisa objetivou aplicar a técnica de uso de drone para mapear e quantificar a cobertura vegetal em três loteamentos periféricos localizados na cidade Paragominas-PA, de modo a avaliar a proporção de cobertura vegetal em cada um, determinar o Índice de Cobertura Vegetal por Habitante (ICVH) para cada loteamento e analisar a distribuição espacial desta vegetação. Para tanto, realizou-se um levantamento aéreo de imagens com utilização de drone, a serem posteriormente processadas para extração da máscara de cobertura vegetal nos softwares Agisoft Photo Scan e ArcMap 10.1. Foram verificados percentuais e índices de cobertura vegetal por habitante de $13,26 \%$ e $5,05 \mathrm{~m}^{2} / \mathrm{hab}$ para o loteamento Laércio Cabeline, $8,16 \%$ e 3,30 $\mathrm{m}^{2} / \mathrm{hab}$ para o Jardim Atlântico e 5,57\% e 10,28 $\mathrm{m}^{2} / \mathrm{hab}$ para o loteamento Ouro Preto. Observou-se também que a maior parte da vegetação presente nas áreas em estudo fica localizada em quintais, distribuídos por todo o espaço mapeado. O Uso do drone possibilitou um levantamento satisfatório da cobertura vegetal.

Palavras-chave: Drone; Loteamentos; Percentual.

\section{ABSTRACT}

An important mechanism involved in the advancement of urbanization is the replacement of vegetation areas by urban equipment, an action that becomes more critical in the peripheries, where the execution of urban planning and maintenance of conditions of comfort and environmental quality tend to be more deficient. Given this, this research aimed to apply the drone technique to map and quantify the vegetation cover in three peripheral allotments located in the city of Paragominas-PA, in order to evaluate the proportion of vegetation cover in each one, to determine the Plant Cover Index per inhabitant (PCIH) for each plot and to analyze the spatial distribution of this vegetation. For that, an aerial survey of images using a drone was carried out, to be later processed for extraction of the mask of vegetal cover in the Agisoft Photo Scan and ArcMap 10.1 software. There were verified percentages and indices of per capita plant cover of $13.26 \%$ and $5.05 \mathrm{~m} 2 /$ inhab for Laércio Cabeline, $8.16 \%$ and $3.30 \mathrm{~m}^{2} /$ inhab. for Jardim Atlântico and $5.57 \%$ and $10,28 \mathrm{~m}^{2} /$ inhabitant for the Ouro Preto subdivision. It was also observed that most of the vegetation present in the study areas is located in backyards, distributed throughout the mapped space. The use of the drone enabled a satisfactory survey of the vegetal cover.

Keywords: Drone; Lots; Percentage.

Recebido em 01.03.2019 e aceito em 18.05.2019

1 Engenheira Ambiental. Programa de Pós-Graduação em Geografia. UFPA. Belém/PA. Email: lu.costa0708@gmail.com.

2 Engenheiro Ambiental. Discente do curso de Especialização em Engenharia de Segurança do Trabalho. Estagiário na Prefeitura Municipal de Paragominas. Paragominas/PA. Email: maycon.lbino@hotmail.com.

3 Engenheira Ambiental. Discente do curso de Especialização em Engenharia de Segurança do Trabalho. São Miguel do Guamá. Email: nayarafarias@outlook.com.

4 Engenheira Ambiental. Belém/PA. Email: lorenaengamb20@gmail.com.

5.Engenheira Ambiental. Discente do curso MBA em Gestão Estratégica de Negócios. Ipixuna do Pará/PA. Email: renatarochax@hotmail.com.

6 Engenheiro Florestal. Mestre em Recursos Hídricos. Profo na UFRA. Paragominas/PA. Email: denison.singeo@gmail.com.

7 Engenheiro Ambiental. Mestre em Geociências. Profo no Instituto Federal do Pará. Itaituba/PA. Email: tuliosilva@id.uff.br. 


\section{INTRODUÇÃO}

Nas últimas décadas, as cidades cresceram rapidamente e de maneira desordenada, isto devido à progressiva mudança do homem do meio rural para o meio urbano. Assim, com a ausência de planejamento adequado, passaram a surgir diversas problemáticas interferentes de maneira expressiva na vida dos cidadãos. Dentre estas, a carência de áreas verdes nas cidades, onde sua falta é bastante notória principalmente devido ao desconforto térmico (PINHEIRO; SOUZA, 2017).

O crescimento da urbanização causa distúrbios significativos na natureza, onde áreas de vegetação nativa são trocadas por equipamentos urbanos, tais como prédios, calçadas, asfalto, veículos à motor, dentre outros. Neste cenário, subsistem reduzidas áreas de vegetação, ou seja, fragmentos dos ambientes originais, os quais, mesmo segregados pela ação do homem, exercem grande função social, na maioria das vezes interligada a fatores como o microclima (MARTINI; BIONDI, 2015).

Logo, a cobertura vegetal urbana caracteriza-se como uma forma de atração de benefícios para a qualidade de vida, pois é capaz de amenizar efeitos como a poluição urbana e o desconforto térmico ocasionado pelas elevadas temperaturas e redução da umidade relativa do ar, além da grande capacidade de reter água no solo (TEIXEIRA; LUCAS, 2014).

Todavia, como defende Ugeda Júnior (2016), o processo de planejamento urbano tradicional - especialmente em países periféricos - não leva em consideração elementos do planejamento da paisagem, deixando assim de considerar indicadores ambientais contextualizados que são capazes de promover maior qualidade de vida nas cidades. Nesse âmbito, a vegetação é mencionada como um fator do qual se deve fazer o máximo proveito em termos de qualidade ambiental, promovendo o respeito e aprimoramento da capacidade suporte local, onde os recursos ambientais devem ser utilizados de forma regulada.

Dada a relevância amplamente assumida da cobertura arbórea - a despeito de sua pouca influência no planejamento urbano brasileiro, mapear a ocorrência de corredores e zonas verdes urbanas passa a ser uma ferramenta de inegável interesse, especialmente para a gestão pública. Espaços arborizados podem ser quantificados e qualificados (BARGOS; MATIAS, 2012), e isto comumente ocorre a partir do levantamento em escala de bairro, por meio de imagens de satélite ou fotografias aéreas capturadas por Aeronaves Remotamente Pilotadas (RPA's, do Inglês Remotely-Piloted Aircraft), drones ou Veículos Aéreos não Tripulados (VANT's) e trabalho de campo. Essas técnicas permitem mapear e quantificar os espaços livres de construções e a cobertura vegetal ainda existente, além de ser possível identificar pontos de risco de enchentes, os tipos de cobertura do solo, déficit de espaços livres e desertos florísticos (áreas com percentual de cobertura vegetal abaixo de $5 \%$ ), tornando possível o desenvolvimento de projetos urbanos visando melhor qualidade ambiental (PINA, 2011). 
Seguindo essa tendência, a pesquisa ora apresentada objetivou aplicar a técnica de uso de drone para mapear e quantificar a cobertura vegetal em três loteamentos periféricos localizados na cidade de Paragominas-PA, de modo a avaliar a proporção de cobertura vegetal em cada um, determinar o Índice de Cobertura Vegetal por Habitante (ICVH) para cada loteamento e analisar a distribuição espacial desta vegetação.

\section{MATERIAL E MÉTODOS}

\section{Área de estudo}

A área de estudo foi definida como os loteamentos Jardim Atlântico, Laércio Cabeline e Ouro Preto, localizados no município de Paragominas, município localizado na mesorregião sudeste do Estado do Pará. O último censo realizado pelo Instituto Brasileiro de Geografia e Estatística (IBGE, 2010), apurou a população do Jardim Atlântico em 7.989 habitantes (10,44\% da população urbana) distribuída em $322.825 \mathrm{~m}^{2}$, resultando em densidade demográfica de 0,025 $\mathrm{hab} / \mathrm{m}^{2}$. Para o loteamento Laércio Cabeline, a população foi de 6.789 habitantes $(8,87 \%$ da população urbana), residentes em uma área de $258.400 \mathrm{~m}^{2}$, o que correspondeu à $0,026 \mathrm{hab} / \mathrm{m}^{2}$. Já para o loteamento de Ouro Preto, o IBGE estimou a população em 2.664 habitantes (3,48\% da população urbana total), em uma área de $490.914 \mathrm{~m}^{2}$, o que correspondeu a uma ocupação de $0,0054 \mathrm{hab} / \mathrm{m}^{2}$ (Figura 1).

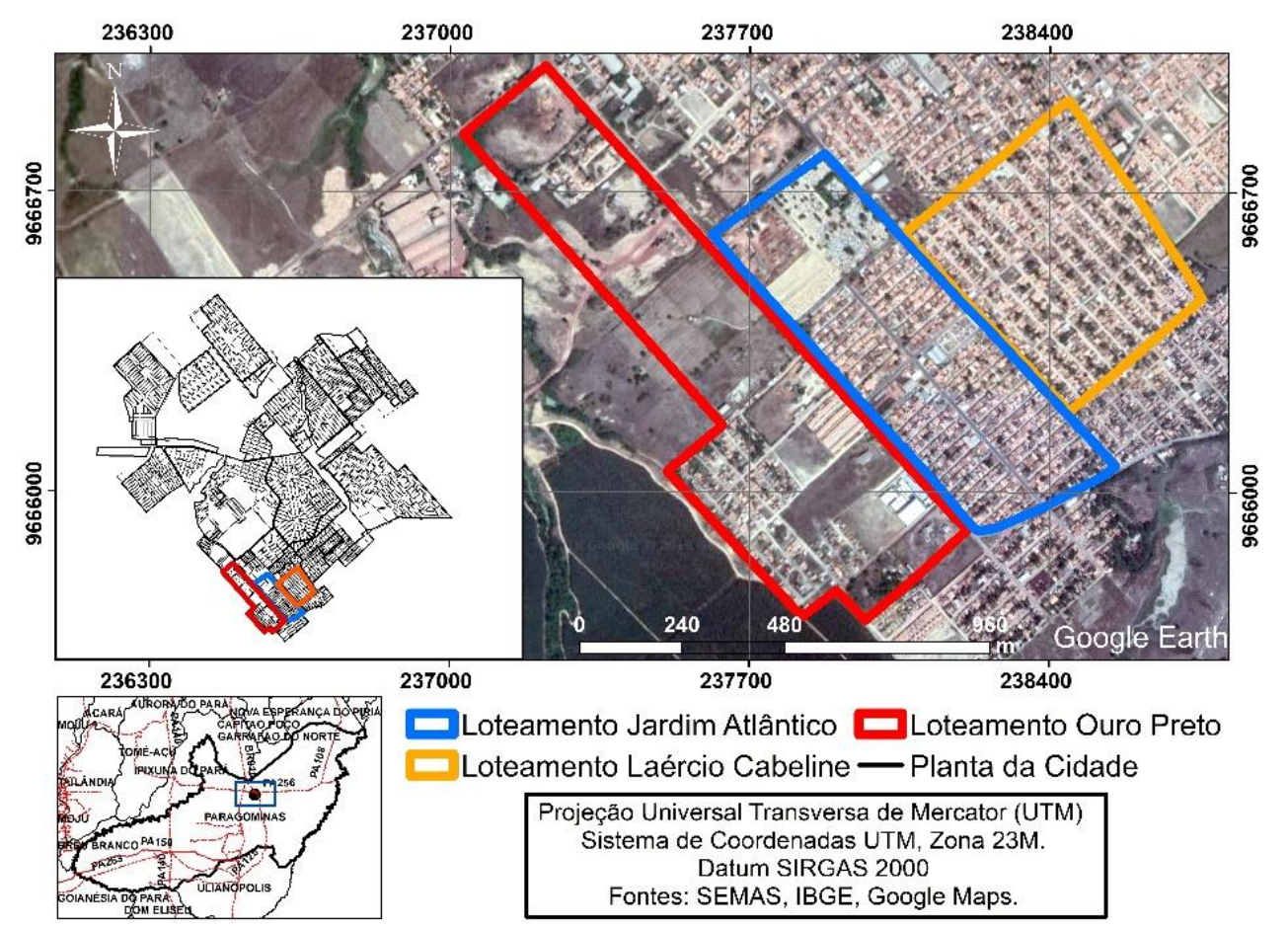

Figura 1. Localização da área de estudo

Figure 1. Location of the study area 


\section{Procedimentos metodológicos}

A metodologia de trabalho consistiu basicamente na captura de imagens de alta resolução espacial através da utilização de um Drone. A seleção desta técnica justifica-se pela alta resolução espacial e atualização proporcionadas por imagens registradas com o uso de um Drone (CORREA et al., 2018).

A fim de alcançar os objetivos do trabalho, foi realizado um mapeamento aerofotogramétrico, com auxílio de um dispositivo de mídia digital a bordo de um Drone modelo Mavic Pro, devidamente cadastrado pelo Sistema de Aeronaves Não Tripuladas (SISANT) da Agência Nacional de Aviação Civil-ANAC, seguindo determinações do regulamento Brasileiro de Aviação Civil Especial - RBAC-E no 94.

O drone Mavic Pro possui $83 \mathrm{~mm}$ de altura, $83 \mathrm{~mm}$ de espessura e $198 \mathrm{~mm}$ de comprimento. O peso do equipamento (com baterias e hélices) é de $734 \mathrm{~g}$. A altura máxima de voo é de 5000 m, com bateria completa. Alcança distância máxima de 15 km, usa os sistemas de posicionamento por satélite GPS/GLONASS, com tempo máximo de voo de 30 minutos a uma velocidade constante de $25 \mathrm{~km} / \mathrm{h}$. As imagens capturadas apresentam dimensão de 4000×3000.

Primeiramente, foi realizado um plano de voo no software Drone Deploy, onde foram determinadas algumas especificações do voo, tais como altitude (172 m), ângulo de captura $\left(90^{\circ}\right)$, cobertura lateral (65\%) e cobertura frontal (75\%). Além disso, foi realizada a delimitação das áreas para a execução do plano de voo. Esta ação foi efetuada no aplicativo Google Earth, de onde foram importados arquivos no formato Keyhole Markup Language (KML) com os polígonos das áreas a serem levantadas em cada voo.

Consequentemente, foi realizado levantamento em campo. Foram executados três voos com tempo médio de 14 minutos cada, para mapeamento da área total dos três loteamentos $\left(1.072 .139 \mathrm{~m}^{2}\right)$, onde foram capturadas 375 imagens, com resolução espacial de $6 \mathrm{~cm}$.

O processamento das imagens foi iniciado no software Agisoft Photo Scan, onde executou-se o alinhamento das mesmas e, posteriormente, criado o Modelo Digital de Elevação (MDE), com definição do sistema de coordenadas. A partir de tais processos, foi criado o ortomosaico das imagens, denominado de ortoimagem. Este, foi salvo e importado para o software Arcmap 10.1, onde foi realizada a classificação do mesmo, de acordo com a metodologia proposta por Correa et al. (2018), denominada Índice de Cobertura Verde Ajustado (ICVA) (Equação 1) implementado pela função raster calculator (calculadora de raster) do ArcMap.

$$
\text { ICVA }=[(\text { pGreen }-p \text { Red } / \text { pGreen }+p \text { Red }) \times L)]
$$

Onde: pRed: reflexão da região vermelha (Red region); pGreen: reflexão da região verde (Green region);

$L$ : abertura da lente do equipamento (graus). 
As bandas ( $p$ Red e pGreen) representam a região dos espectros correspondentes às cores vermelho e verde, do visível. As bandas espectrais utilizadas no cálculo do índice apresentam uma relação entre a maior absorção da energia eletromagnética pela vegetação ativa na faixa espectral do vermelho e a maior reflexão da região verde. $\mathrm{O}$ índice varia de -1 a +1 , onde valores negativos estão associados à maior presença de solo exposto, água e construções e valores positivos à presença de vegetação (CORREA et al., 2018).

Após o processo de classificação da ortoimagem, foi realizada uma reclassificação, para extrair somente a classe representativa da cobertura vegetal de porte médio a alto, com aplicação da ferramenta reclassify do Arcmap, onde foram selecionados os valores dos intervalos correspondes à classe vegetação. Com tal resultado, foi feita a conversão do arquivo de saída do formato raster para vetor (polígono), com o intuito de quantificar a área correspondente à cobertura vegetal, calculada a partir da tabela de atributos do arquivo shapefile resultante.

Foi efetuada a determinação do percentual (proporção) da área de cada loteamento coberto por vegetação. Os percentuais foram analisados tomando-se como referência os parâmetros determinados por Oke (1973), que sugere o percentual ideal de 30\% de cobertura vegetal em áreas urbanas. Caso este valor seja inferior a 5\%, há caracterização das áreas como regiões desérticas (OKE, 1973), o que implica em consequências negativas para a qualidade ambiental. Além disso, foi realizado o cálculo do índice de cobertura vegetal por habitante (ICVH) (Equação 2), tomando como base a metodologia proposta por Nucci e Cavalheiro (1999).

$$
I C V H=\frac{\text { Cobertura vegetal da área urbana }\left(m^{2}\right)}{\text { Número de habitantes da área urbana }}
$$

Equação 2

Por fim, realizou-se análise da forma como a vegetação estava distribuída no espaço urbano. Essa ação foi auxiliada por interpretação/visualização da ortoimagem gerada anteriormente e considerando os modelos de distribuição espacial propostos por $\operatorname{Jim}$ (1989). Em tal proposta, o autor usa como critério de classificação da cobertura os diferentes tamanhos e formatos das manchas (Figura 2), além dos diferentes graus de conectividade e proximidade. 
1. ISOLATED (ISOLADO)
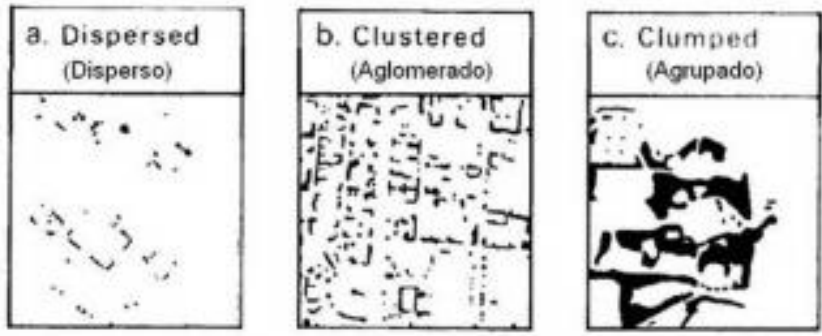

2. LINEAR (LINEAR
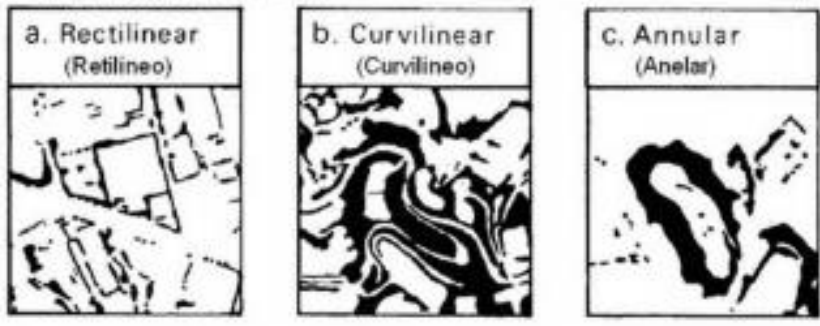

3. CONNECTED (CONECTADO)
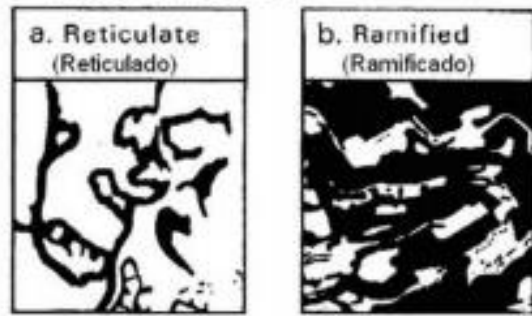

Cobertura vegetal

Esquema de dassificaçio para cobetura vegetal urbana. Am (1999)
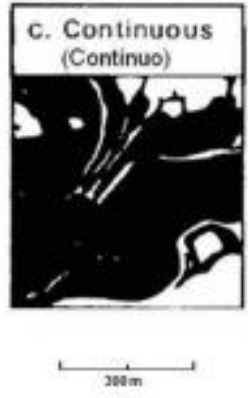

Fonte: $\operatorname{Jim}(1989)$.

Figura 2. Modelos de espacialização de cobertura vegetal

Figure 2. Models of plant cover distribution

\section{RESULTADOS E DISCUSSÃO}

\section{Proporção de cobertura vegetal}

De acordo com a análise dos dados obtidos com a aplicação da equação proposta por Correa et al. (2018), verificou-se que o loteamento Laércio Cabeline apresentou maior área de cobertura vegetal, com percentual de 13,27\% (34.285 $\left.\mathrm{m}^{2}\right)$, em relação a área do loteamento, seguido pelos loteamentos Jardim Atlântico e Ouro Preto, com percentuais de 8,17\% $\left(26.370 \mathrm{~m}^{2}\right)$ e 5,58\% (27.358 $\left.\mathrm{m}^{2}\right)$, respectivamente. Apesar do loteamento Laércio Cabeline apresentar a menor área $\left(258.400 \mathrm{~m}^{2}\right)$ em relação aos outros dois, o quantitativo de cobertura vegetal neste loteamento foi maior (Figura 3). 
600.000

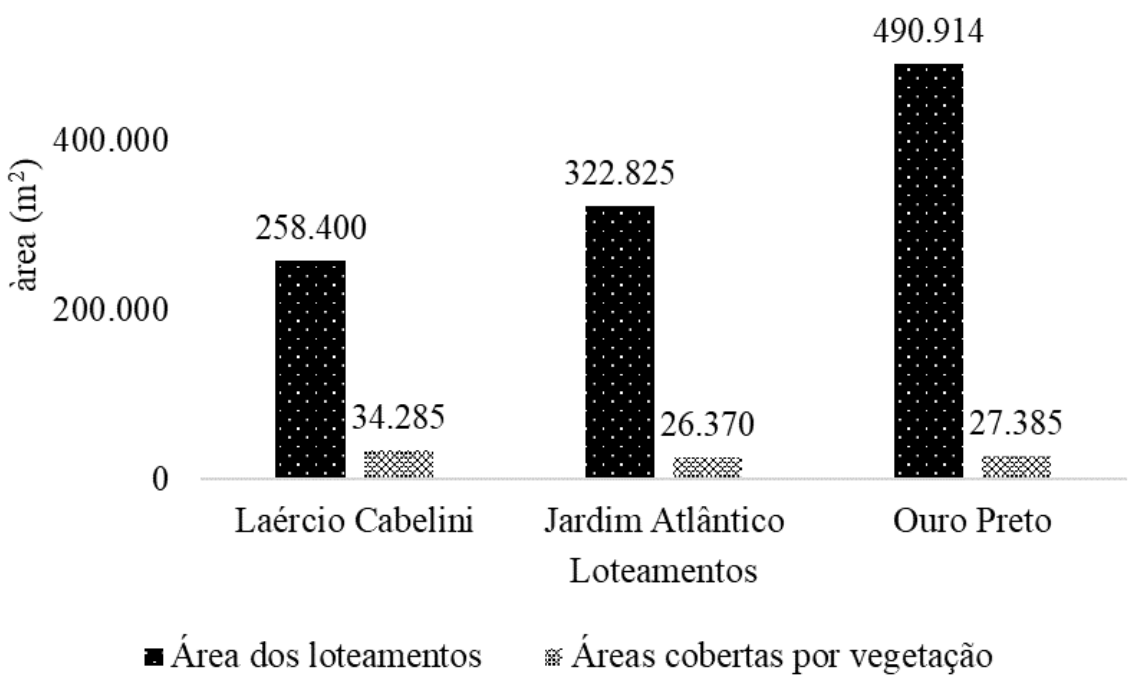

Figura 3. Relação entre áreas dos loteamentos e áreas cobertas por vegetação Figure 3. Relation between areas of lots and areas covered by vegetation

A análise dos dados obtidos indicou uma diferença maior do quantitativo de cobertura vegetal entre os loteamentos Laércio Cabeline e Jardim Atlântico $\left(7.915 \mathrm{~m}^{2}\right)$ e menor entre os loteamentos Jardim Atlântico e Ouro Preto $\left(1.015 \mathrm{~m}^{2}\right)$. O fato de o loteamento Laércio Cabeline apresentar menor área territorial e maior quantitativo de cobertura vegetal pode estar relacionado com as formas de uso e ocupação do solo (maior percentual de unidades residenciais, com um número significativo de habitantes (6.789). Um maior número de residências (pode) implicar em número maior de quintais, onde geralmente ocorre o plantio de árvores em regiões periféricas urbanas.

Considerando o percentual de cobertura vegetal proposto por Oke (1973) para áreas urbanas, percebe-se que nos loteamentos analisados os resultados ficaram consideravelmente abaixo do ideal (30\%), entretanto nenhuma das áreas apresentou proporção de vegetação que possam caracteriza-las como desertos florísticos, ou seja, cobertura vegetal abaixo de 5\% (OKE, 1973). Somente no loteamento Ouro Preto, o percentual verificado ficou muito próximo do valor limite, com diferença de 0,58\%.

Em estudo realizado por Rodrigues et al. (2014), nos bairros Nazaré e Guamá, na cidade de Belém-PA, foram verificados percentuais de cobertura vegetal semelhantes aos dos loteamentos em estudo, sendo 11,35\% para o bairro Nazaré e 5,42\% para o bairro Guamá. Os percentuais observados para os bairros, de acordo com os autores, tiveram influência do planejamento das ruas. Os autores inferiram que o primeiro bairro apresenta características de áreas urbanas planejadas, com ruas largas e arborizadas, enquanto o segundo fica localizado em áreas de baixada, sem controle e desorganizadas, com características de bairro não 
planejado, onde a densidade populacional é alta, as vias estreitas, a arborização pouca (ou nenhuma) e faltam espaços públicos e de infraestrutura.

Os percentuais reduzidos de áreas de cobertura vegetal em ambientes urbanos configuram-se como problemáticas que influenciam de forma direta o déficit de sombreamento, a baixa dos valores de umidade relativa do ar e altos valores de temperatura, estabelecendo uma relação direta entre arborização e conforto térmico amplamente demonstrada na literatura científica, valendo mencionar os estudos de Silva, Xavier e Alvarez (2015), Martini et al. (2014) e Martelli e Rodrigues (2015).

\section{Índice de cobertura vegetal por habitante (ICVH)}

Os dados obtidos a partir da aplicação do ICVH para os loteamentos indicaram que o loteamento Ouro Preto apresentou o maior índice (10,28 $\left.\mathrm{m}^{2} / \mathrm{hab}\right)$, seguido por Laércio Cabelini $\left(5,05 \mathrm{~m}^{2} / \mathrm{hab}\right)$ e Jardim Atlântico (3,30 $\left.\mathrm{m}^{2} / \mathrm{hab}\right)$. O índice mais elevado no primeiro loteamento tem relação com o fato deste possuir um número consideravelmente menor de habitantes em relação aos outros dois.

Os índices verificados indicam que as áreas periféricas da cidade de Paragominas carecem de elementos naturais que proporcionem melhor qualidade de vida aos habitantes dessas áreas. Ainda que se pese a falta de uma referência segura para avaliar a relação área verde/habitante, a Sociedade Brasileira de Arborização Urbana (SBAU) recomenda uma proporção ideal considerando apenas as áreas verdes públicas destinadas à recreação, a qual é de $15 \mathrm{~m}^{2}$ de área verde por habitante (SBAU, 1996). Portanto, pode-se afirmar que, a nível de bairro, os índices encontrados certamente encontram-se abaixo do ideal.

Apesar do quantitativo reduzido, os índices verificados em loteamentos periféricos geralmente ainda são maiores do que em áreas centrais, haja vista que as formas de uso do solo em bairros residenciais, de característica periférica, além do histórico de ocupação, proporcionam maiores espaços para o desenvolvimento de vegetação em comparação com áreas centrais urbanas, que detém paisagens densamente ocupadas por construções (LINDENMAIER; SOUZA, 2015).

\section{Distribuição espacial da cobertura vegetal}

A análise de distribuição da cobertura vegetal, possibilitada pela alta resolução espacial da ortoimagem, indicou que a vegetação presente nos loteamentos está distribuída principalmente em áreas de domínio particular (quintais). No loteamento Laércio Cabelini, essa distribuição foi verificada por toda a área de estudo, como pode ser observado na Figura 4. 


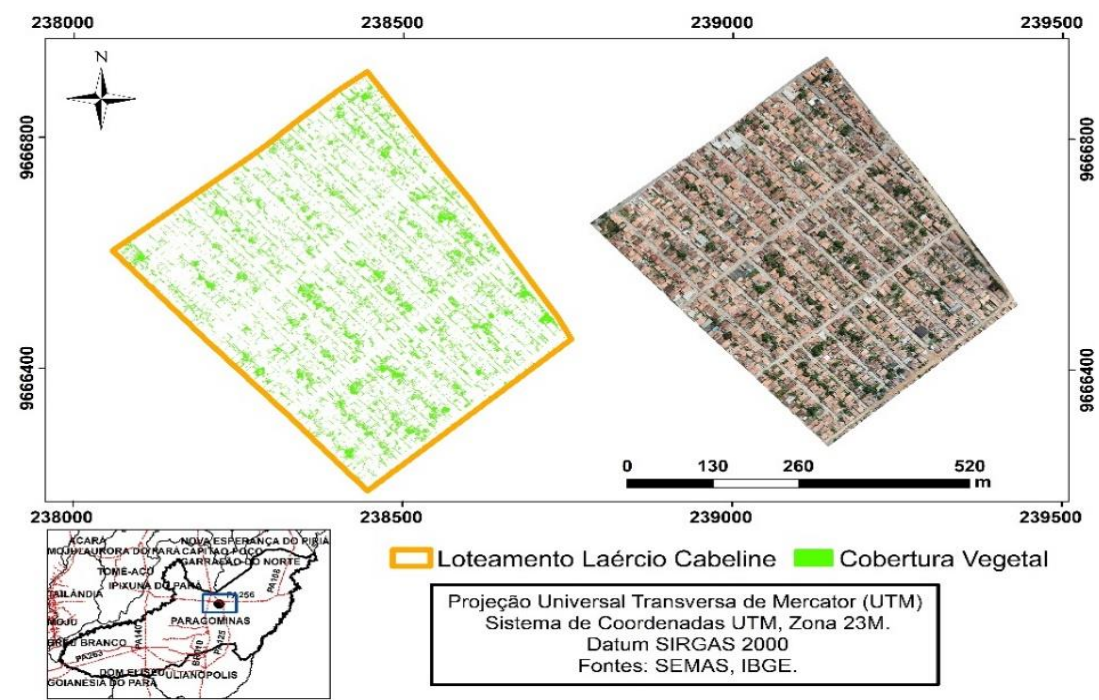

Figura 4. Cobertura vegetal do loteamento Laércio Cabeline, Paragominas-PA

Figure 4. Cover map of Laércio Cabeline loting, Paragominas-PA

No loteamento Laércio Cabelini não há presença de canteiros e praças com vegetação, o que pode estar relacionado, sobretudo, com a falta de planejamento das ruas e com o perfil de uso e ocupação do solo. Neste caso, as áreas não vegetadas consistem basicamente em espaços construídos e vias públicas, contribuindo para a formação de um padrão de pequenas manchas com pouca conectividade, configurando a variante que Jim (1989) denominou de clustered, esquema formado por pequenos grupos de árvores misturadas a estruturas construídas.

Para o loteamento Jardim Atlântico, também se verificou distribuição de cobertura vegetal por toda área de estudo (Figura 5). A diferença em relação à configuração do bairro Laércio Cabelini se deve à ausência ainda maior de contiguidade, o que marca um isolamento do verde que é quase pulverizado, aproximando-se do padrão dispersed (disperso), o qual consiste em pequenas e quase equidimensionais unidades, frequentemente compostas por árvores isoladas, largamente espalhadas na matriz de estruturas artificiais (JIM, 1989). Alguns vazios de vegetação se destacam, como as áreas descampadas a noroeste, onde se encontra um pátio de desdobramento de madeira e uma vasta área aberta, onde possivelmente há perspectiva de uso imobiliário. Mais ao centro, algumas construções empresariais de maior porte substituem a vegetação, que poderia ser mais densa na praça localizada na mesma região. 


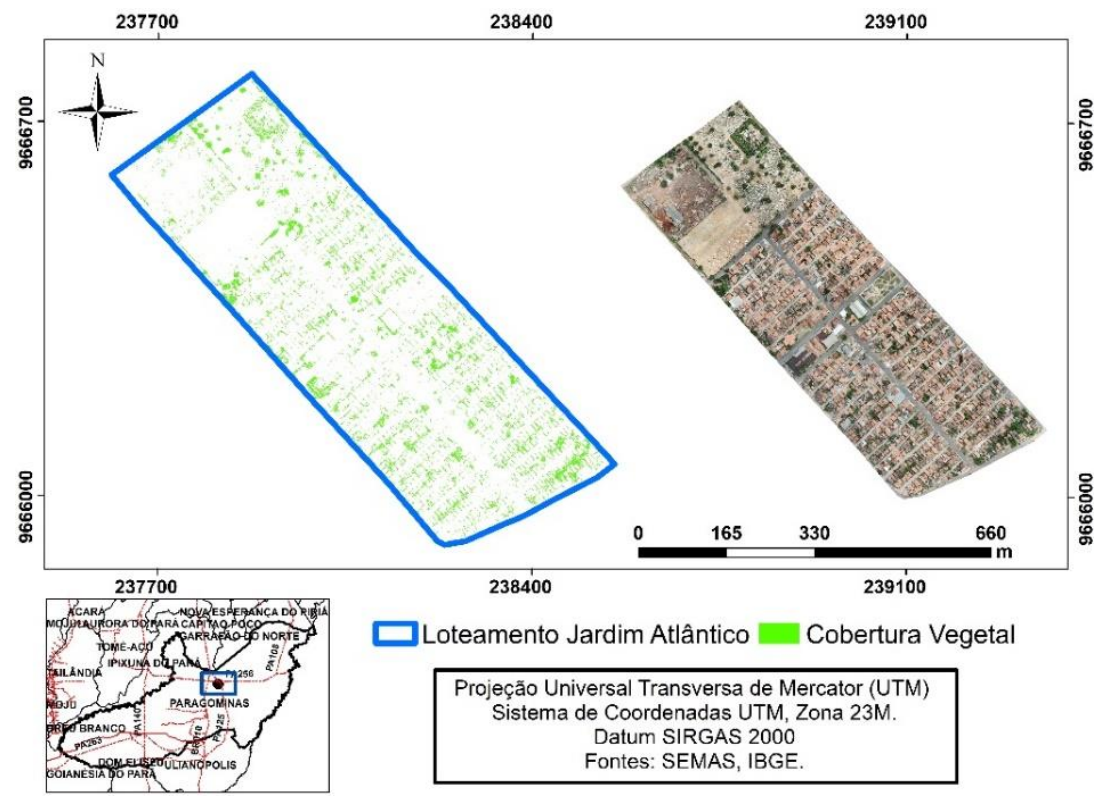

Figura 5. Cobertura vegetal do loteamento Jardim Atlântico, Paragominas-PA Figure 5. Vegetal cover of Jardim Atlântico loting, Paragominas-PA

No loteamento Ouro Preto, a cobertura vegetal se apresentou de maneira menos distribuída e se deu de forma escassa, com destaque para pequenas manchas nas regiões sudoeste-sul e noroeste (Figura 6), enquanto a área central do loteamento careceu de áreas arborizadas.

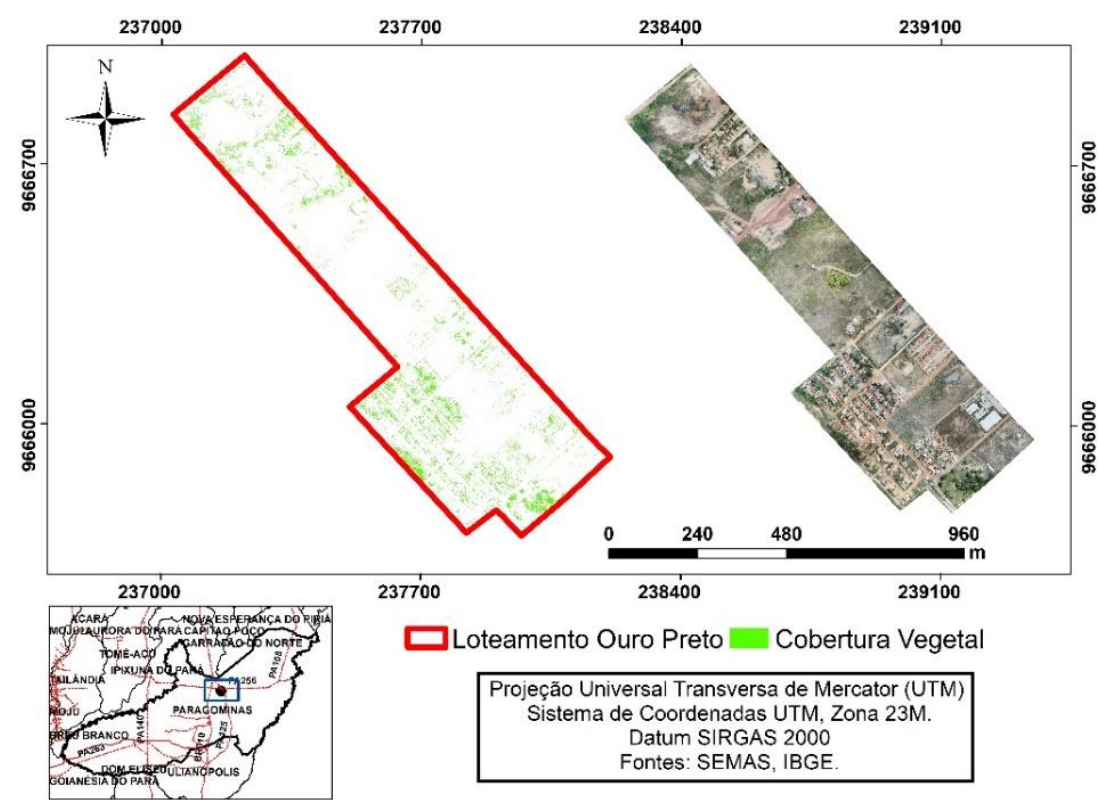

Figura 6. Cobertura vegetal do loteamento Ouro Preto, Paragominas-PA Figure 6. Vegetal cover of Ouro Preto loting, Paragominas-PA

De forma semelhante aos outros dois loteamentos, a vegetação presente nessa área está disposta em quintais de residências e também em locais sem utilização. Todavia, a ausência 
pronunciada e a configuração claramente dispersa das árvores, impõe um padrão isolado que só se torna menos claro em alguns pontos com limitada concentração de copas. Relativamente, o déficit arbóreo aqui se consolida, na fronteira do perímetro urbano, onde o uso residencial é ainda incipiente. Nesta área, ainda há vastos terrenos abertos possivelmente aguardando compradores - ou já negociados - e/ou utilizados para a agricultura ou pecuária, ao lado de alguns pátios industriais.

Com os espaços desabitados sob outros regimes de uso, a menor densidade populacional no loteamento Ouro Preto não favoreceu de modo significativo a arborização, levando a concluir que o uso habitacional influenciou positivamente a cobertura arbórea no caso da região estudada. Pode-se compreender esta relação como um resultado do tipo de arborização predominante nos três loteamentos, que se baseou na vegetação erguida no interior de lotes residenciais, em detrimento da arborização de vias e equipamentos públicos. O que a princípio pode parecer contraditório - haja vista que a relação entre áreas menos povoadas e cobertura vegetal tende a ser inversa - pode ser explicado por diferenças de uso da terra. Principalmente em locais com maior vocação agrícola, os limites da cidade configuram um espaço de transição do rural para o urbano onde nem sempre a menor pressão demográfica favorece o surgimento e persistência de vegetação arbórea-arbustiva. No caso da área estudada, é evidente a transformação da paisagem à medida em que se avança para a borda do perímetro urbano, onde lotes edificados começam a perder espaço para terrenos fabris, projetos habitacionais incipientes e pastagens.

As diferenças de cobertura vegetal arbórea entre diferentes usos da terra se manifestaram de forma estatisticamente significativa em relações envolvendo variáveis biofísicas e socioeconômicas referentes à cidade de Los Angeles, CA, estabelecidas por Clarke, Jenerette e Davila (2013). Comparando a cobertura de vegetação herbácea, arbustiva e arbórea em setores com diferentes regimes de uso, os autores observaram que as árvores são particularmente mais frequentes nas áreas predominantemente residenciais, em oposição a regiões mais comerciais e com maior infraestrutura de transporte. Isto é, um perfil classicamente residencial tal como exibido pelo loteamento Laércio Cabeline, onde aspectos comuns deste tipo de região se manifestam, como a localização (não tão próxima do centro comercial e das vias principais) e a definição mais expressiva em quarteirões.

A contribuição dos quintais para a arborização urbana se mostrou igualmente importante no mapeamento realizado por Oliveira et al. (2015) na cidade de Vila Velha - ES, onde a classe "Arborização residencial" respondeu pela maior parte da área arborizada (9,31\%), a frente da "Arborização viária" (3,13\%), "privada" (1,26\%), "da orla" $(0,18 \%)$ e "de cemitérios" $(0,07 \%)$. 0 importante papel que os quintais de residências urbanas desempenham na manutenção da cobertura vegetal das cidades é uma relação já demonstrada por estudos como o de Troy et al. 
(2007) na cidade de Baltimore, nos E.U.A., onde 90\% do dossel urbano estava situado em áreas privadas, as quais também representaram $85 \%$ das áreas de potencial plantio. Além do incremento de cobertura de porte arbóreo, a arborização residencial destaca-se também como fonte de maior biodiversidade, tal como verificado por Clarke, Jenerette e Davila (2013) nas áreas residenciais da cidade de Los Angeles, CA.

Como citam Haase, Jänicke e Wellmann (2019), ainda que apenas os moradores de lotes arborizados tenham o acesso direto garantido a suas áreas, estas prestam importantes serviços ecossistêmicos para a coletividade, como regulação do clima, resfriamento do ar, recreação local e bem-estar humano. Evidências de efeitos positivos indiretos sobre a saúde pública foram levantados por Van Den Bosch e Ode Sang (2017), que associaram positivamente, em diferentes graus, o contato com ambientes naturais no meio urbano com a amenização de problemas de saúde, através de redução do nível de stress, obesidade, calor e ruído, e incremento de atividade física e de benefícios emocionais. Em seu turno, Strohbach, Haase e Kabisch (2009) destacam a felicidade, satisfação com a vida e a biodiversidade urbana como efeitos positivos do contato com ambientes naturais.

Sobre a relação entre localização e cobertura vegetal, resultados interessantes foram apontados pelo estudo de Phan et al. (2012) na cidade de Montreal, Canadá. Os autores encontraram resultados que sugerem relação inversa entre setores com maior proporção de pessoas de baixa renda e integrantes de minorias (em menor grau) - boa parte na periferia urbana - e a cobertura vegetal total, especialmente a parcela localizada em espaços públicos. Novamente, contudo, os quintais desempenharam um papel notável na investigação realizada por Phan et al. (2012), amenizando o efeito da parca arborização dos espaços públicos em zonas periféricas.

Vale ressaltar que apesar dos dados produzidos neste estudo, o vigente Plano Diretor de Desenvolvimento Urbano (PDDU) do município de Paragominas, instituído no ano de 2006 e atualmente em revisão, possui como uma de suas diretrizes gerais promover a melhoria e ampliação do serviço de arborização pública, reconhecendo, em seu Art. 68, os benefícios proporcionados pelas áreas verdes no que tange ao conforto térmico, amenização de poeira, ruídos e stress e melhoria da paisagem (PARAGOMINAS, 2006). O PDDU previu, ainda, a criação de incentivos à arborização e ao ajardinamento de áreas públicas e privadas, em clara suposição da necessidade de mecanismos que levem os agentes particulares e o próprio poder público a contribuírem para a expansão da cobertura arbórea local. Percebe-se, no entanto, que passados 12 anos os termos formalizados não puderam ser plenamente traduzidos em realidade física, especificamente quando consideramos o nível de arborização dos bairros aqui mapeados, em especial no que se refere às áreas e vias públicas. 


\section{CONCLUSÕES}

A utilização do drone no mapeamento dos loteamentos permitiu uma quantificação real da cobertura vegetal presente nos mesmos, fator possibilitado pela alta resolução espacial das imagens capturadas. Isto demonstra que a aplicação dessa tecnologia é um importante subsídio para identificação "rápida" das condições ambientais e estruturais dos ambientes urbanos.

A cobertura vegetal é um componente ambiental urbano pouco considerado nos loteamentos Laércio Cabeline, Jardim Atlântico e Ouro Preto, no município de Paragominas. O quantitativo vegetal em tais espaços urbanos se mostrou inferior a 30\% (percentual em relação às áreas totais dos mesmos), com valores próximos da caracterização de desertos florísticos.

Quanto ao ICVH, este apresentou valores reduzidos, sendo que apenas o loteamento Ouro Preto apresentou um valor mais elevado (10, $\left.28 \mathrm{~m}^{2} / \mathrm{hab}\right)$. Tais resultados indicam que, a quantidade de vegetação presente nessas áreas é inferior ao quantitativo populacional, o que influencia na diminuição da qualidade de vida.

No que se refere à distribuição espacial da vegetação, esta, não se apresentou em áreas de praças, canteiros de vias ou em áreas verdes públicas, ficando praticamente restrita a quintais urbanos e lotes sem uso, com característica aglomerada para o loteamento Laércio Cabelini e dispersa para o Jardim Atlântico e Ouro Preto.

Nesse contexto, vale ressaltar a importância de melhor planejamento e respectiva execução, em áreas periféricas dos ambientes urbanos, no qual haja consideração da importância da vegetação para melhores condições de vida dos habitantes e amenização das condições ambientais urbanas.

\section{REFERÊNCIAS}

BARGOS, D. C.; MATIAS, L. F. Mapeamento e análise de áreas verdes urbanas em Paulínia (SP): estudo com a aplicação de geotecnologias. Sociedade \& Natureza, Uberlândia, v. 24, n.1, p. 143-156, 2012.

CLARKE, L. W.; JENERETTE, G. D.; DAVILA, A. The Luxury of Vegetation and the Legacy of Tree Biodiversity in Los Angeles, CA. Landscape and Urban Planning, Michigan, v. 116, p. 4859, 2013.

CORREA, D. L.; VASCONCELOS, M. A. M.; BITTENCOURT, P. C. S.; RODRIGUES, J. Index Set Green Cover Method for Automated Identification of Vegetation. International Journal Of Advanced Engineering Research And Science, Jaipur, v. 5, n. 8, p.83-86, 2018.

HAASE, D.; JÄNICKE, C.; WELLMANN, T. Front and back yard green analysis with subpixel vegetation fractions from earth observation data in a city. Landscape and Urban Planning, Michigan, v. 182, p. 44-54, 2019. 
INSTITUTO BRASILEIRO DE GEOGRAFIA E ESTATÍSTICA (IBGE). Grade estatística. Disponível em:<ftp://geoftp.ibge.gov.br/recortes_para_fins_estatisticos/grade_estatistica/censo 2010/>. Acesso em: 30 ago. 2018.

JIM, C. Y. Tree-Canopy Characteristics and Urban Development in Hong Kong. Geographical Review, New York, v. 79, n. 2, p. 210, 1989.

LINDENMAIER, D. S.; SOUZA, B. S. P. Avaliação da cobertura vegetal arbórea em Cachoeira do Sul/RS: índice e distribuição espacial do elemento verde na paisagem urbana. Geografia Ensino \& Pesquisa, Santa Maria, v. 19, n. 3, p. 79-88, 2015.

MARTELLI, A.; RODRIGUES, A. Urban tree of Itapira-SP: Perspectives for environmental education and its influence on thermal comfort. Revista Eletrônica em Gestão, Educação e Tecnologia Ambiental, Santa Maria, v. 19, n. 2, p. 1018-1031, 2015.

MARTINI, A.; BIONDI, D. Microclima e conforto térmico de um fragmento de floresta urbana em Curitiba, PR. Floresta e Ambiente, Rio de Janeiro, v. 22, n. 2, p. 182-193, 2015.

MARTINI, A.; BIONDI, D.; BATISTA, A.; ZAMPRONI, K.; VIEZZER, J.; GRISE, M.; LIMA NETOO, E. Percepção da população sobre o conforto térmico proporcionado pela arborização de ruas de Curitiba-PR. Floresta, Curitiba, v. 44, n. 3, p. 515-524, 2014.

NUCCI, J.C.; CAVALHEIRO, F. Cobertura vegetal em áreas urbanas - conceito e método. GEOUSP, São Paulo, n.6, p. 29-36, 1999.

OKE, T. R. City size and urban heat island. Atmospheric environment, New York, v. 7, n. 8, p. 769-779, 1973.

OLIVEIRA, F. S.; SANTOS, A. R.; SILVA, A. G.; GLERIANI, J. M.; GONÇALVES, W.; TEIXEIRA, T. R.; RODRIGUES, G. F.; RIBEIRO, C. A. A. S.; BRANCO, E. R. F.; SILVA, R. G.; DALFI, R. L.; MOURA, M. M. Mapeamento da Vegetação Urbana da Cidade de Vila Velha, ES. In: Santos, A. R.; RIBEIRO, C. A. A. S.; PELUZIO, J. B. E.; PELUZIO, T. M. O.; SANTOS, G. M. A. D. A.; MAGALHÃES, I. A. L. (Orgs.). Geotecnologias \& análise ambiental: aplicações práticas. 1ed. Alegre, ES: CAUFES, 2015, v. 1, p. 23-40.

PARAGOMINAS. Prefeitura Municipal. Lei no 597, de 04 de outubro de 2006. Institui o Plano Diretor de Desenvolvimento Urbano do município de Paragominas e dá outras providências. Disponível em:<https://camaraparagominas.pa.gov.br/plano-diretor>. Acesso em: 19 dez. 2018.

PHAN, T.-T.-H.; APPARICIO, P.; SÉGUIN, A-M.; LANDRY, S.; GAGNON, M. Spatial distribution of vegetation in Montreal: an uneven distribution or environmental inequity? Landscape and Urban Planning, Michigan, v. 107, n. 3, p. 214-224, 2012.

PINA, J. H. A. A influência das áreas verdes urbanas na qualidade de vida: o caso dso Parques do Sabiá e Victório Siquierolli em Uberlândia-MG. 2011. 185 f. Dissertação (Mestrado) - Curso de Geografia. Unversidade Federal de Uberlândia, Uberlândia, 2011.

PINHEIRO, C. R.; SOUZA, D. D. A importância da arborização nas cidades e sua influência no microclima. Revista Gestão \& Sustentabilidade Ambiental, Florianópolis, v. 6, n. 1, p. 67-82, 2017.

RODRIGUES, J. E. C.; LUZ, L. M.; SARAIVA, J. S. Análise morfológica dos bairros de Nazaré e Guamá no processo de redução das áreas verdes urbanas no município de Belém-PA. In: 
CONGRESO IBEARMERICANO DE ESTUDIOS TERRITORIALES Y AMBIENTALES, 6., 2014, São Paulo. Anais... São Paulo: Estudios Territoriales, 2014. p. 2813 - 2838.

SILVA, B. A.; XAVIER, T. C.; ALVAREZ, C. E. A influência da vegetação no conforto térmico para a condição microclimática de Vitória (ES). Periódico Técnico e Científico Cidades Verdes, Tupã-SP, v. 3, n. 8, 2015.

SOCIEDADE BRASILEIRA DE ARBORIZAÇÃO URBANA - SBAU. "Carta a Londrina e Ibiporã". Boletim Informativo, v.3, n.5, p.3, 1996.

STROHBACH, M. W.; HAASE, D.; KABISCH, N. Birds and the city: urban biodiversity, land use, and socioeconomics. Ecology and Society, Nova Scotia, v. 14, n. 2, p. 31-46, 2009.

TEIXEIRA, P. H. L.; LUCAS, T. P. B.; A influência da vegetação em um microclima da cidade de Belo Horizonte, MG. Caderno de Geografia, Belo Horizonte, v. 24, n.4, p. 56-72, 2014.

TROY, A. R.; GROVE, J. M.; O'NEIL-DUNNE, J. P. M.; PICKETT, S. T. A.; CADENASSO, M. L. Predicting Opportunities for Greening and Patterns of Vegetation on Private Urban Lands. Environmental Management, Zurich, v. 40, n. 3, p. 394-412, 2007.

UGEDA JÚNIOR, J. C. Planejamento da paisagem e planejamento urbano: reflexões sobre a urbanização brasileira. Revista Mato-Grossense de Geografia, Cuiabá, v. 17, n. 1, p. 101-116, 2016.

VAN DEN BOSCH, M.; ODE SANG, Å. Urban natural environments as nature-based solutions for improved public health - a systematic review of reviews. Environmental research, Bethesda MD, v. 158, p. 373-384, 2017. 